\title{
Viability of Using Local Waste Materials in the Production of High-Performance and Self-Compacting Concrete
}

\author{
Sayed Mohamad Soleimani, Abdel Rahman Alaqqad, \\ Ali Behbehani, Mhd Hazem Al-Swwaf and Najem Al-Matroud \\ Department of Civil Engineering, Australian College of Kuwait, West Mishref, Kuwait
}

\author{
Article history \\ Received: 23-11-2019 \\ Revised: 24-12-2019 \\ Accepted: 01-01-2020 \\ Corresponding Author: \\ Sayed Mohamad Soleimani \\ Department of Civil \\ Engineering, Australian College \\ of Kuwait, West Mishref, \\ Kuwait \\ Email: s.soleimani@ack.edu.kw
}

\section{Introduction}

Factories in Kuwait generate waste material that can be repurposed. Some of the most prominent industries in Kuwait are the ceramics and structural steel production industries. According to Halicka et al. (2013) and Medina et al. (2012), the ceramics industry generates plenty of waste due to strict internal quality control standards. They also consider the fragile nature of finished ceramic products which can be damaged during the manufacturing and transportation processes. The local structural steel industry produces Electric-Arc Furnace Slag (EAFS) as a by-product of reducing iron ore in its furnaces. Although steel slag has no use in the industry, it is known to have cementitious properties when it is crushed. Studies have shown that EAFS is characteristically harder and has a density that is approximately $20-25 \%$ higher than conventional blast furnace slag (Australasian (Iron and Steel) Slag Association, 2019). Studies by Juan et al. (2010), Senthamarai and Manoharan (2005) and Gomes and de Brito (1999) have shown that concrete containing crushed ceramics as a partial replacement for aggregates in a normal concrete mix show similar, if not better, fresh properties when compared to a concrete made with conventional materials. Additionally, studies by Anderson et al. (2016) and Awoyera et al. (2016) have shown that the introduction of ceramic wastes in coarse and fine aggregate forms improves the fresh and hardened properties when introduced to a standard concrete mix. Arulsivanantham and Gokulan (2017) define self-compacting concrete as a new category of high-performance concrete that is characterized by its high workability, which ensures a high flow rate that allows the concrete to flow evenly through restricted sections. Additionally, Khayat (1999) states that selfcompacting concrete is largely resistant to segregation and can be cast quicker than conventional concrete in construction sites. The aim of this study is to investigate the effects of introducing EAFS, ceramic powder and ceramic aggregates into a benchmark self-compacting high-performance concrete mix and examining its fresh and hardened properties.

\section{Methodology}

\section{Choice of Quality Control Tests}

Self-Compacting Concrete (SCC) has a higher workability than conventional concrete. In order to verify that the sample of concrete at hand is selfcompacting concrete, the following ASTM quality control tests were selected to be conducted on the samples of fresh SCC:

J-Ring Test: To determine the ability of SCC to flow around reinforcements to ensure workability, correct placement and to show the SCC susceptibility to segregation. The results from this test are compared with a traditional slump flow test to check for any variation, which would indicate the SCC susceptibility to blocking (ASTM International, 2017). 
L-Box Test: To demonstrate the SCC's ability to flow through tight reinforcement configurations. After the SCC flows through the L-Box, the ratio of the height of the concrete at each end of the L-Box is taken (British Standards Institution, 1998a).

V-Funnel Test: A test used to measure the SCC's workability. It is the time required for a batch of SCC to flow through a constricted V-shaped container. The test is performed when the SCC when is freshly mixed and after it has been allowed to sit in the V-Funnel for 5 minutes, which should show the SCC's susceptibility to segregate (British Standards Institution, 1998b).

Afterwards, the SCC was cast in $100 \times 200 \mathrm{~mm}$ cylinders and left to cure in submerged conditions for periods in the range of 3-28 days.

To test the SCC compressive strength, unbonded neoprene pads and steel caps were used when the compressive strength was expected to be less than 80 MPa, whereas sulfur capping was used to prepare the samples for when the compressive strength was expected to be $80 \mathrm{MPa}$ and higher.

\section{Development of Benchmark Mix}

The study began with the determination of a suitable self-compacting and high-performance concrete mix to be used as a benchmark mix. The effects of adding EAFS and various ceramic additives can be studied. It is worth noting that the effects of each additive have been investigated separately in this paper. The fresh and hardened properties of various mixes were measured and compared, as shown in the following figures.

As shown Fig. 1, the benchmark mix had identical diameters when tested for both slump flow and J-Ring flow. Additionally, the benchmark mix meets the criteria for SCC, which is a diameter of at least $50 \mathrm{~cm}$ for both slump and J-Ring flow, as well as to not have more than a $2 \mathrm{~cm}$ difference in the diameter.

The L-Box Test results (Fig. 2) show that the benchmark mix had ideal workability, seeing as the ratio of the benchmark mix's height at each end of the L-Box were identical, which gave a ratio of 1.0 , which met the workability requirements for a concrete mix to be considered an SCC.

The V-Funnel Test results (Fig. 3) show that the benchmark mix had undesirable viscosity at both tests. It should be noted that the difference between the two tests should ideally not exceed $10 \mathrm{sec}$.

Multiple samples of the benchmark mix were tested at different submerged curing ages, with tests occurring at 3 , $7,14,21$ and 28 days. The results of the compressive strength tests are shown in Fig. 4 with a trend line. The benchmark mix had an average 28-day compressive strength of $90.0 \mathrm{MPa}$. The benchmark mix's mix design proportions are shown in Table 1.

\section{Use of Ceramic Waste}

Waste ceramic products were repurposed and used in two forms: Ceramic Waste Fine Aggregate (CWFA) was used as a partial replacement of sand and Ceramic Waste Coarse Aggregate (CWCA) was used to partially replace $3 / 16$ " aggregates. The wasted ceramics were placed in a Los Angeles Abrasion machine and were subjected to iterations of 1000 revolutions using 12 steel charges, which were then sieved through US Standard Sieves No. 4 and No. 200 to obtain the CWCA and CWFA, respectively. Each ceramic additive was investigated separately: CWCA was used to replace up to $20 \%$ of the coarse aggregate and CWFA was used to replace up to $20 \%$ of the sand used in the mix. Both additives were introduced to the mix in increments of $5 \%$. The physical parameters of the CWCA and CWFA used in the mix are shown in Table 2.

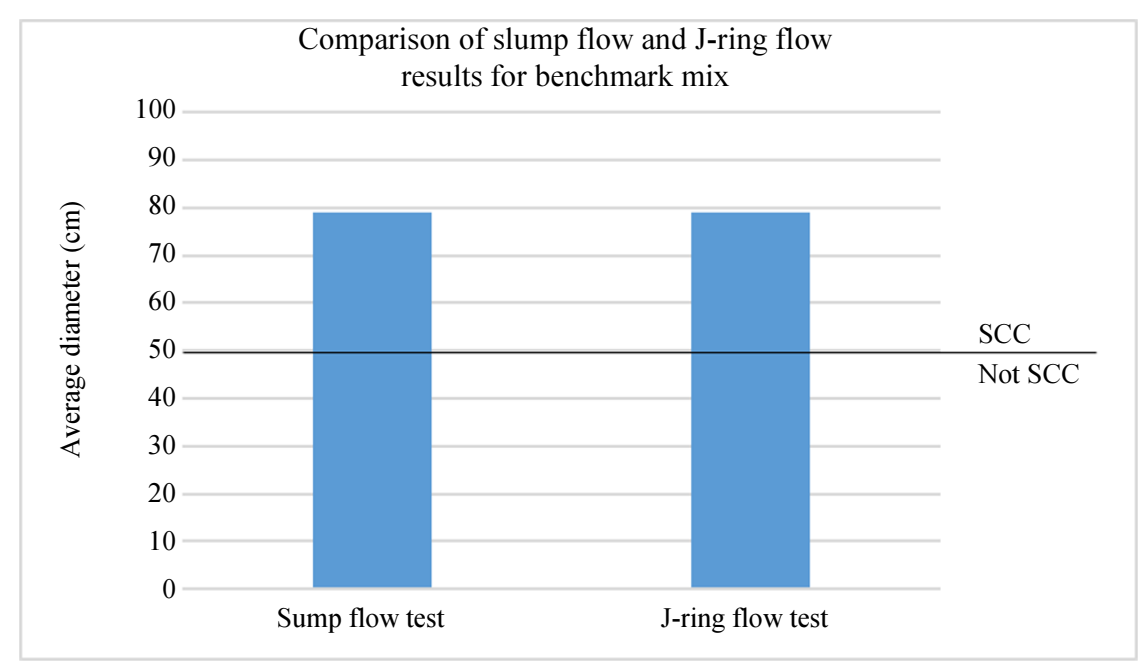

Fig. 1: Comparison of slump flow and j-ring flow for the benchmark mix 


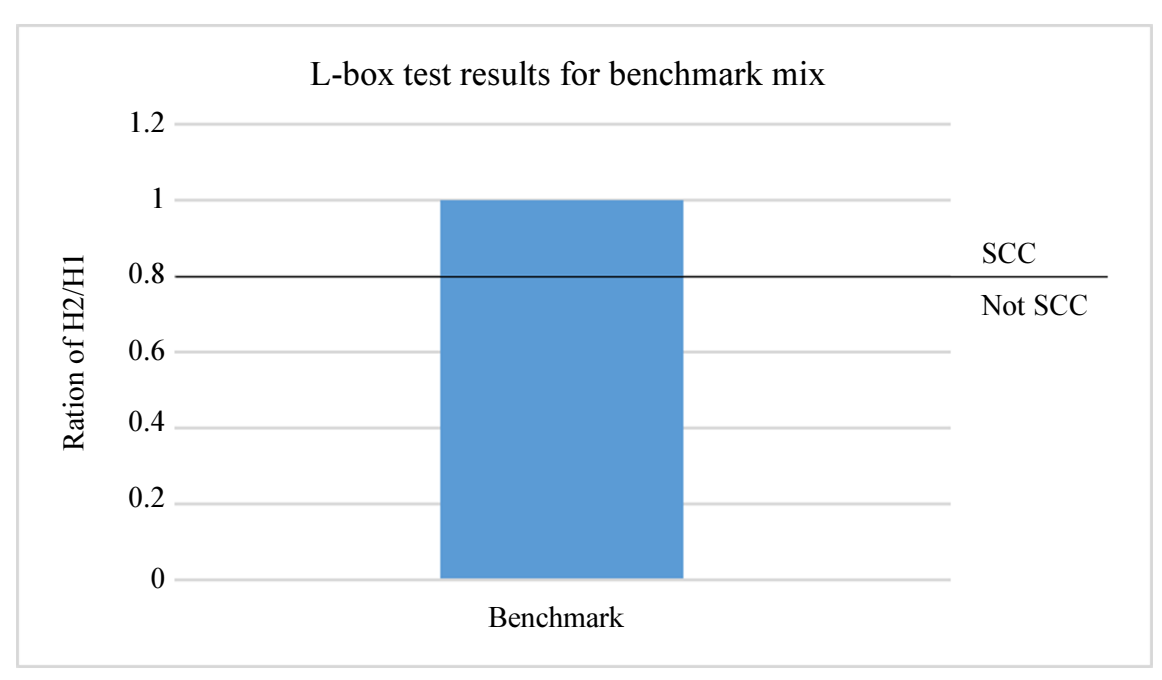

Fig. 2: L-box test results for benchmark mix

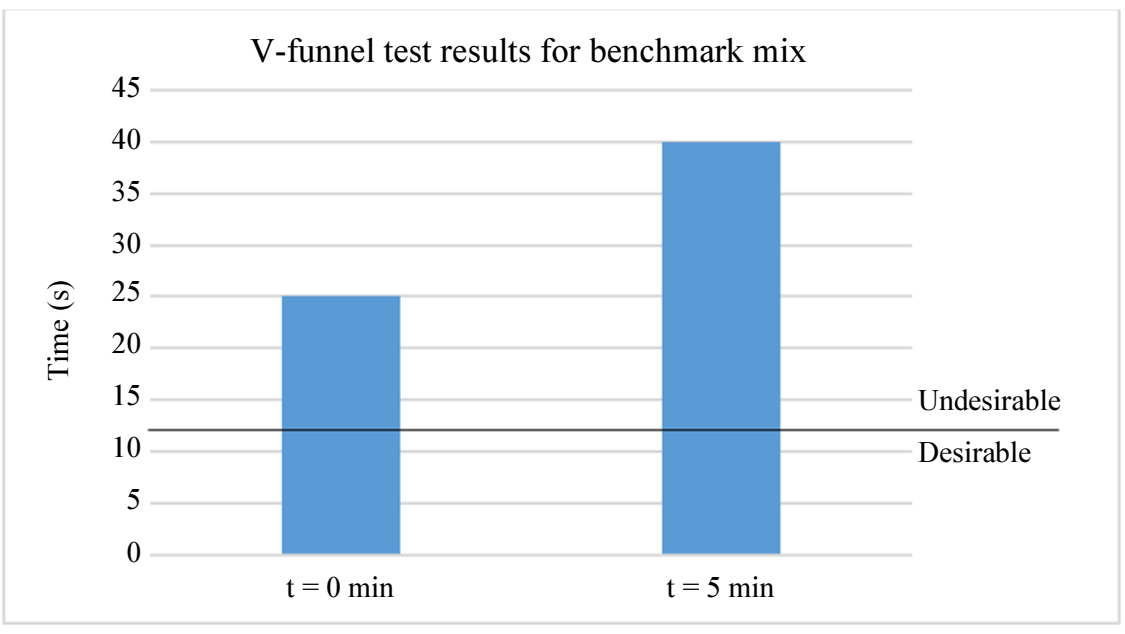

Fig. 3: V-Funnel test results for benchmark mix

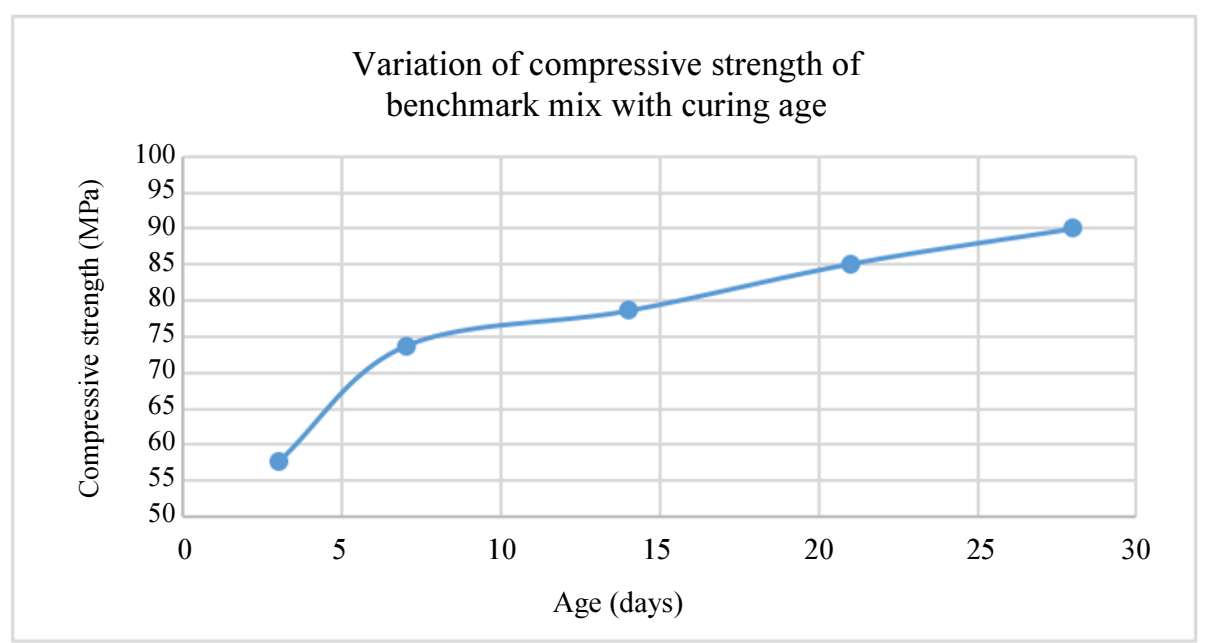

Fig. 4: Variation of compressive strength of benchmark mix with curing age 
Table 1: Mix design proportions of benchmark mix

\begin{tabular}{ll}
\hline Material & Quantity \\
\hline Cement $\left(\mathrm{kg} / \mathrm{m}^{3}\right)$ & 550 \\
Silica Fume $\left(\mathrm{kg} / \mathrm{m}^{3}\right)$ & 40 \\
Fly Ash $\left(\mathrm{kg} / \mathrm{m}^{3}\right)$ & 60 \\
Sand $\left(\mathrm{kg} / \mathrm{m}^{3}\right)$ & 600 \\
$3 / 8^{\prime \prime}$ Coarse Aggregate $\left(\mathrm{kg} / \mathrm{m}^{3}\right)$ & 360 \\
$3 / 16 "$ Coarse Aggregate $\left(\mathrm{kg} / \mathrm{m}^{3}\right)$ & 720 \\
Water $\left(\mathrm{kg} / \mathrm{m}^{3}\right)$ & 169 \\
Water/Binder Ratio & 0.26 \\
Water/Cement Ratio & 0.32 \\
Sika ${ }^{3}$ ViscoCrete ${ }^{3}-5070(\mathrm{~L})$ & 2.2 \\
\hline
\end{tabular}

Table 2: Physical parameters of ceramic additives

\begin{tabular}{ll}
\hline Parameter & Value \\
\hline 3/16" Ceramic Waste Coarse Aggregate (CWCA): & \\
Loose Bulk Density $\left(\mathrm{g} / \mathrm{cm}^{3}\right)$ & 1.295 \\
Compacted Bulk Density $\left(\mathrm{g} / \mathrm{cm}^{3}\right)$ & 1.434 \\
Bulk Specific Gravity & 2.401 \\
SSD Specific Gravity & 2.421 \\
Apparent Specific Gravity & 2.450 \\
Absorption (\%) & 0.84 \\
Ceramic Waste Fine Aggregate (CWFA): & \\
Absorption (\%) & 0.08 \\
Fineness & 100 \\
\hline
\end{tabular}

Table 3: Physical Parameters of EAFS.

\begin{tabular}{ll}
\hline Parameter & Value \\
\hline Loose Bulk Density $\left(\mathrm{g} / \mathrm{cm}^{3}\right)$ & 1.750 \\
Compacted Bulk Density $\left(\mathrm{g} / \mathrm{cm}^{3}\right)$ & 1.902 \\
Bulk Specific Gravity & 3.502 \\
SSD Specific Gravity & 3.550 \\
Apparent Specific Gravity & 3.629 \\
Absorption (\%) & 0.853 \\
\hline
\end{tabular}

\section{Use of EAFS}

EAFS was used to partially replace the $3 / 8$ " aggregates used in the benchmark mix. EAFS was obtained from the factory in aggregate form and was sieved through US Standard Sieve No. 3/8" to obtain suitably-sized aggregates. The effects of using EAFS were studied with dosages of up to $20 \%$ in increments of $5 \%$. The physical parameters of the EAFS used are shown in Table 3.

\section{Results and Discussion}

\section{Effects of Using CWFA and CWCA on Fresh Properties}

As shown in Fig. 5, the introduction of CWCA and CWFA into the benchmark mix neither affects the passing ability of the SCC nor do they subject it to any significant segregation. In any case, all mixes containing CWCA or CWFA met the criteria for SCC.

As shown in Fig. 6, the introduction of CWCA and CWFA into the benchmark mix does not affect the flow- ability of the SCC, which was shown by satisfactory results in the L-Box Test, where all mixes exceeded the required $\mathrm{H} 2 / \mathrm{H} 1$ ratio of 0.8 .

Figure 7 shows that the introduction of CWCA and CWFA into the benchmark mix had mixed results. In any case, all mixes showed undesirable viscosity as they exceeded the maximum time limit of $12 \mathrm{~s}$.

It is interesting to note that the initial introduction of CWCA to the benchmark mix initially increased the time required to clear the $\mathrm{V}$-Funnel, but then as the dosage of CWCA increased the time required to clear the V-Funnel decreased. This was the case up to $20 \% \mathrm{CWCA}$, which saw a complete reversal of the trend. This trend was observed at $\mathrm{t}=0$ minutes, $\mathrm{t}=5$ minutes, as well as in the difference between the two.

As for CWFA, its introduction at a dosage of $5 \%$ initially improved the time required to clear the VFunnel, made it worse at a dosage of $10 \%$, then improved it again with dosages of $15 \%$ and $20 \%$. Again, this trend was observed at $\mathrm{t}=0$ minutes, $\mathrm{t}=5$ minutes, as well as the difference between the two.

\section{Effects of Using CWFA and CWCA on Hardened Properties}

Figure 8 shows the effects of introducing various dosages of CWCA into the benchmark mix, whereas Fig. 9 shows the effect of adding various CWFA dosages.

It is evident that introducing CWCA at any dosage improves the rate of strength gain in the concrete mix, which is shown in how steep the slope of the graph is. It is shown that introducing 5\% CWCA into the benchmark mix made it have a consistent rate of strength gain for the first 21 days. Additionally, all dosages but the $15 \%$ CWCA showed an improvement in the 28-day compressive strength of the mix. The results for $15 \%$ CWCA can be considered anomalous.

As for the CWFA trials, it is clear that introducing $20 \%$ CWFA into the benchmark mix showed an improvement in the rate of strength gain over the benchmark mix, while none of the mixes showed any significant improvement in their 28-day compressive strength over the benchmark mix.

\section{Effects of Using EAFS on Fresh Properties}

Figure 10 shows the results of the slump flow and JRing flow test results of concrete mixes containing various EAFS dosages. All mixes exhibited satisfactory results for both tests and easily met the SCC requirements.

Figure 11 shows the results of the L-Box Test for mixes containing various EAFS dosages. It is shown that introducing EAFS into the benchmark mix does not affect the flow-ability of the SCC, which was shown by satisfactory results, where all mixes were unaffected as compared to the benchmark mix and exceeded the required $\mathrm{H} 2 / \mathrm{H} 1$ ratio of 0.8 . 


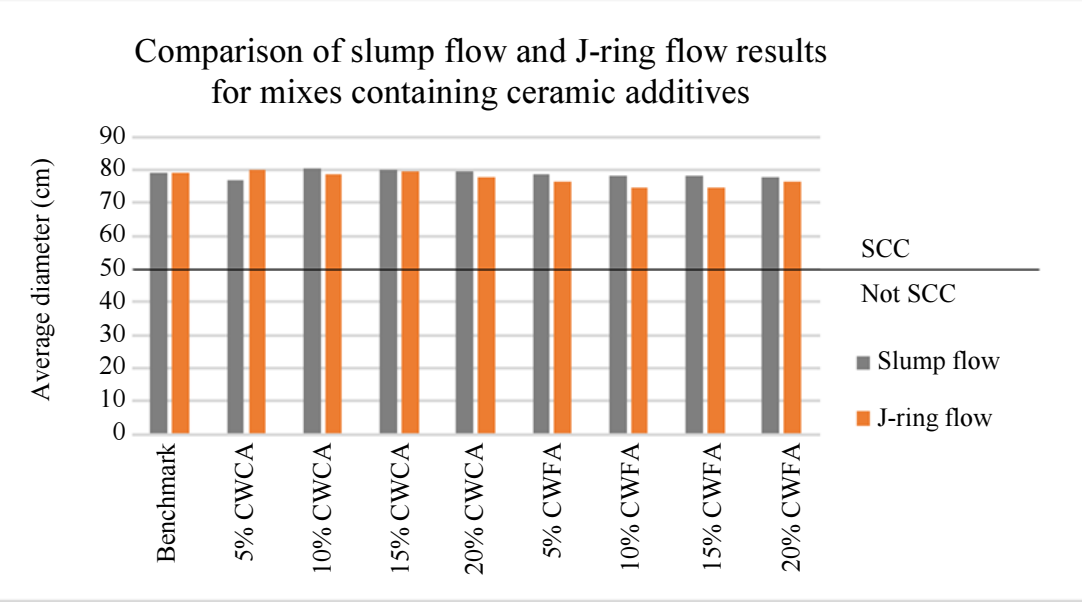

Fig. 5: Comparison of slump flow and j-ring flow results for mixes containing ceramic additives

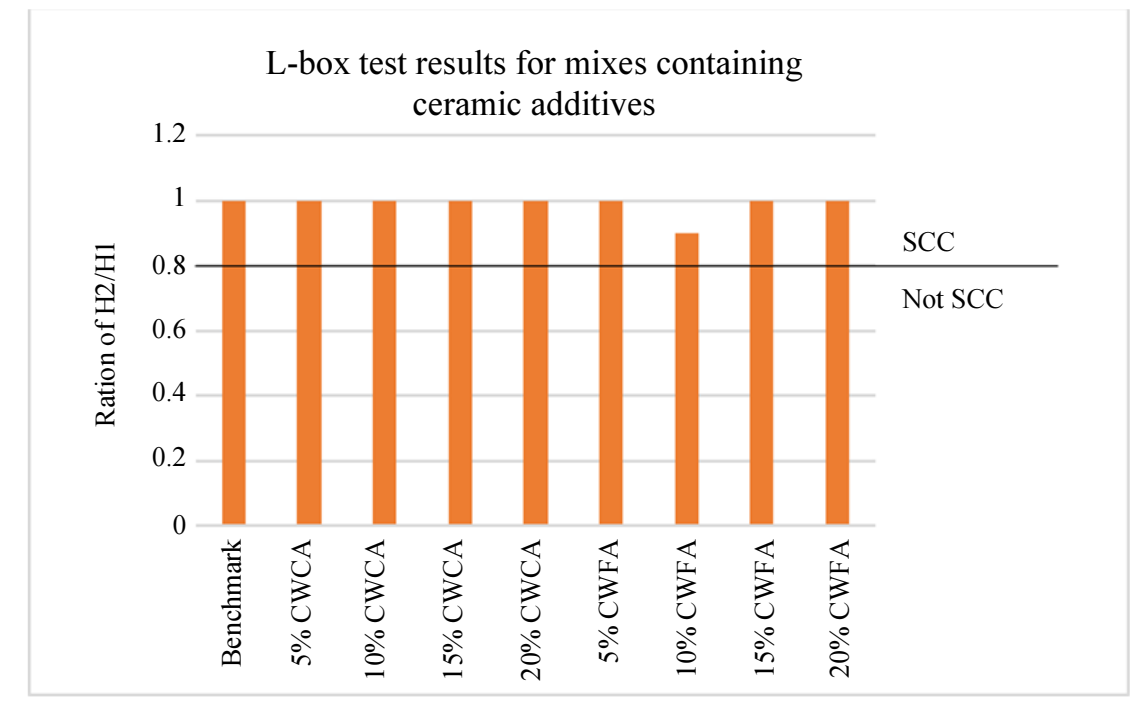

Fig. 6: L-box test results for mixes containing ceramic additives

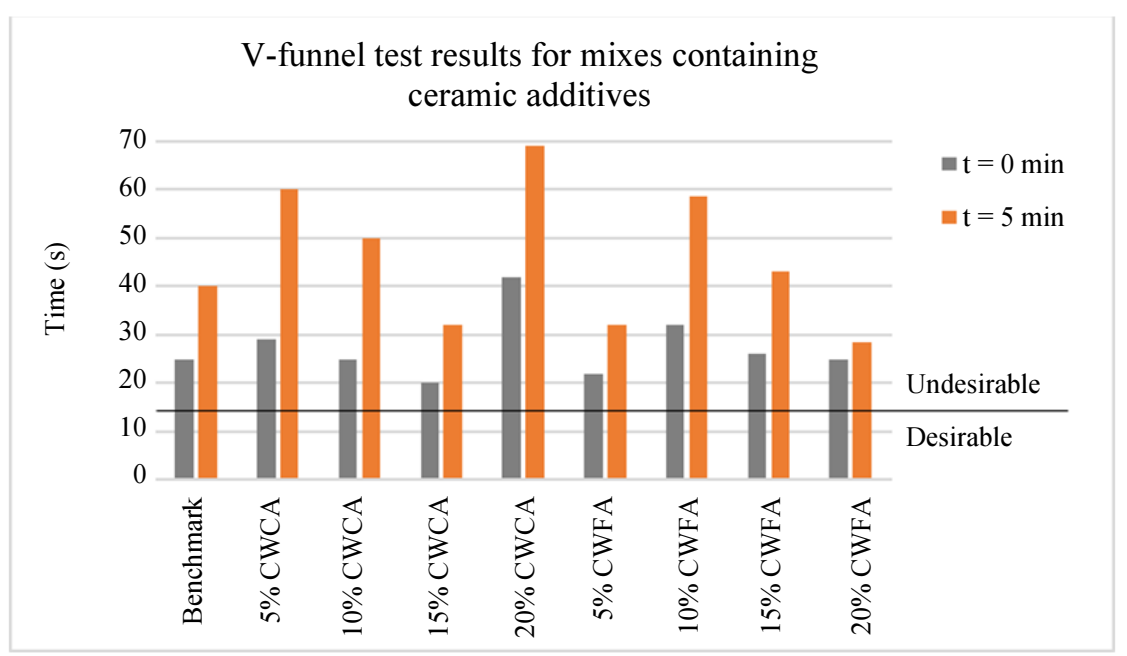

Fig. 7: V-funnel test results for mixes containing ceramic additives 


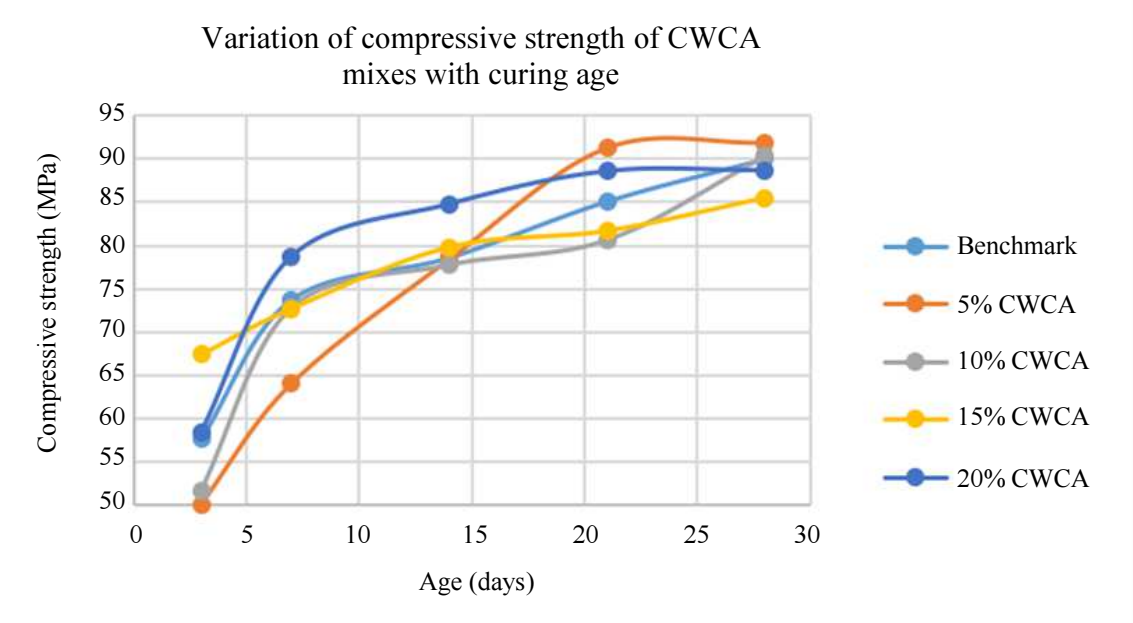

Fig. 8: Variation of compressive strength of CWCA mixes with curing age

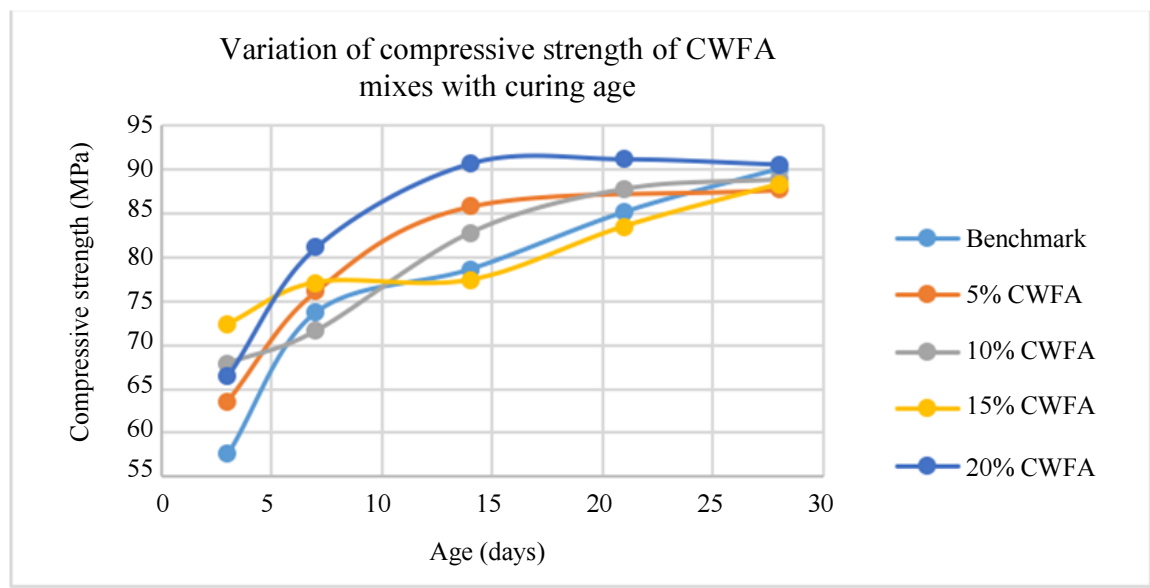

Fig. 9: Variation of compressive strength of CWFA mixes with curing age

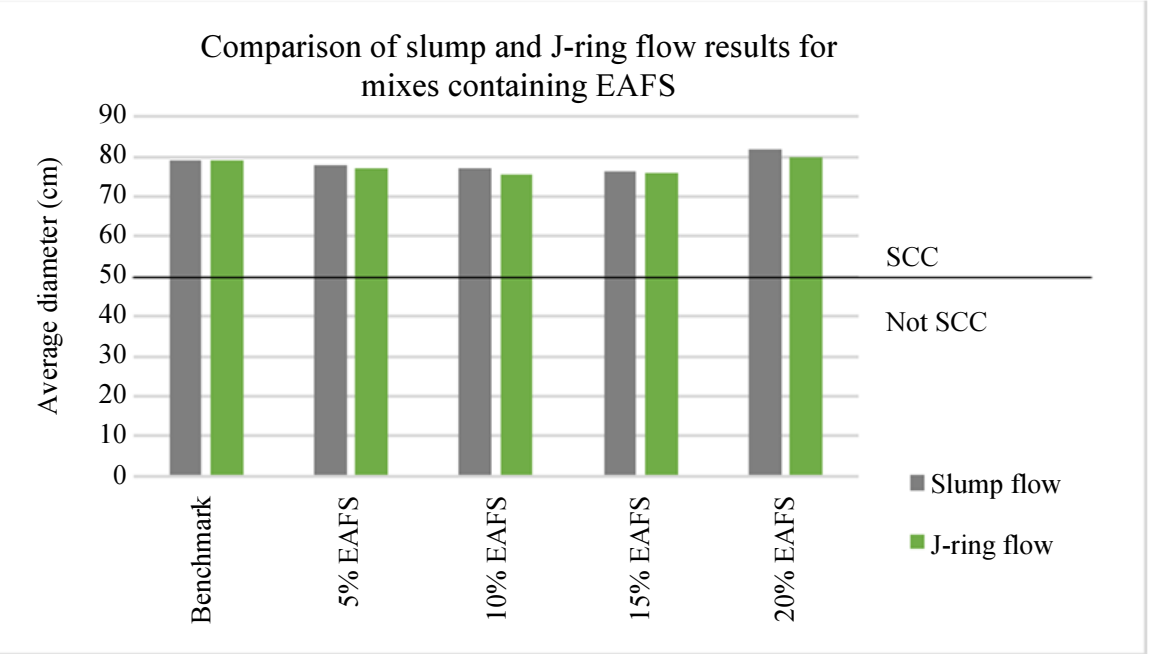

Fig. 10: Comparison of slump flow and J-ring flow results for mixes containing EAFS 


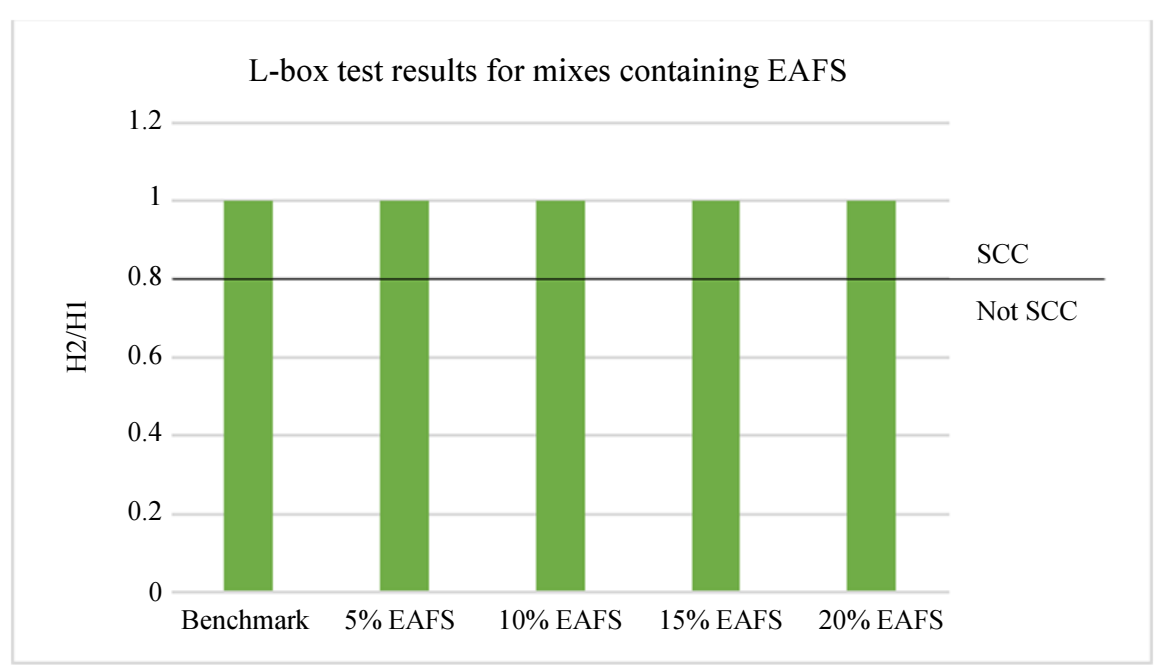

Fig. 11: Comparison of L-box test results for mixes containing EAFS

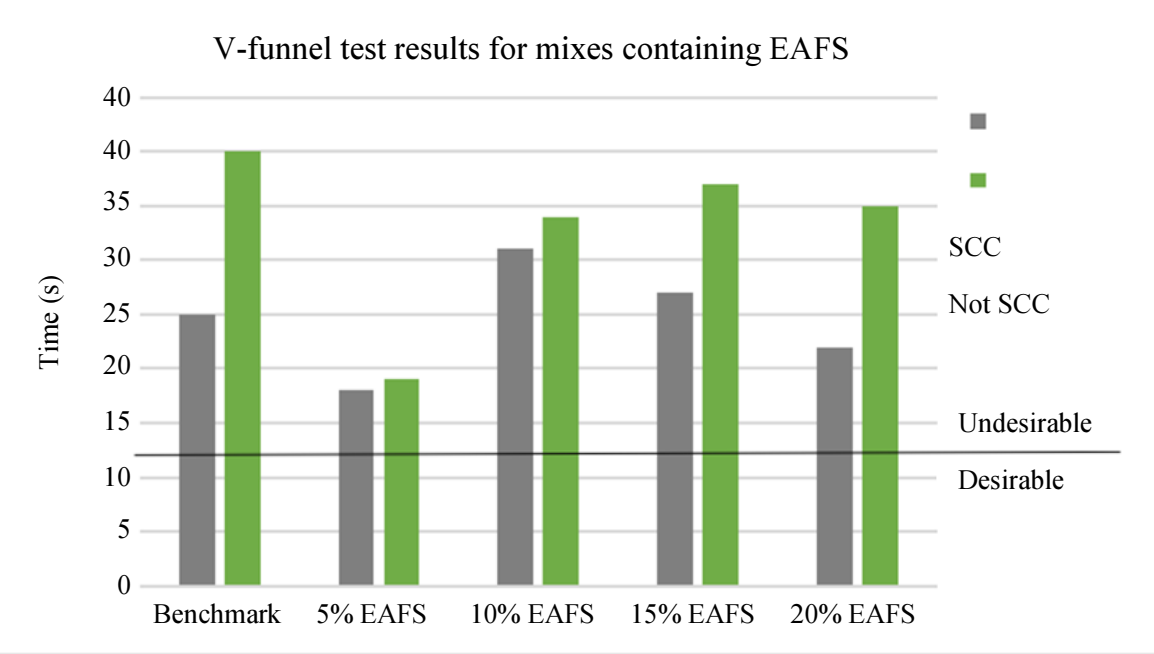

Fig. 12: V-Funnel test results for mixes containing EAFS

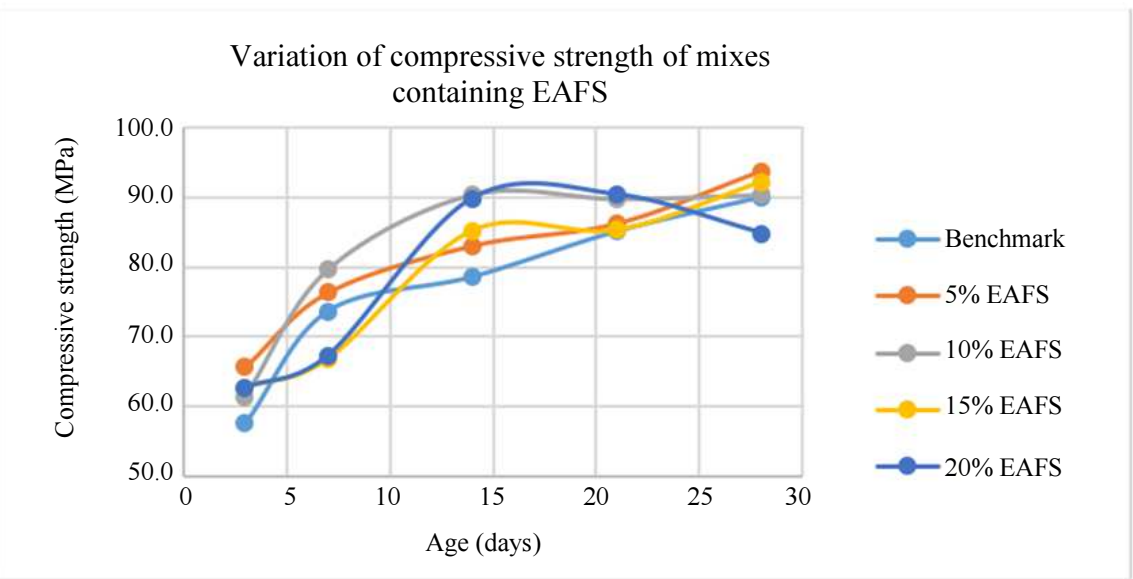

Fig. 13: Variation of compressive strength of mixes containing EAFS 
Figure 12 shows that the introduction of EAFS into the benchmark mix had mixed results. Whereas introducing $5 \%$ EAFS improved the viscosity of the mix, all other dosages showed similar test results compared to the benchmark mix, if not worse. While there may be a slight improvement in the time it takes the SCC to clear the V-Funnel at a dosage of $20 \%$ EAFS, the time difference between $\mathrm{t}=0$ minutes and $\mathrm{t}=5$ minutes increases as the dosage of EAFS increases, which indicates that the presence of EAFS in the mix makes the SCC more susceptible to segregation. In any case, all mixes including the benchmark mix showed undesirable viscosity as they exceeded the maximum time limit of $12 \mathrm{~s}$.

\section{Effects of Using EAFS on Hardened Properties}

Figure 13 shows the variation of compressive strength of mixes containing various dosages of EAFS compared to the benchmark mix. It is evident that, with a few anomalies, the introduction of EAFS at any dosage improves the compressive strength of the benchmark concrete mix. This can be attributed to the rough surface texture of the EAFS. The rate of strength gain remains largely unaffected by the introduction of the EAFS.

\section{Conclusion}

The results of this study show that it is feasible to utilize waste materials sourced from Kuwaiti factories to produce sustainable replacements of conventional materials in the production of self-compacting, highperformance concrete. The fresh and hardened properties of multiple SCC mixes containing various dosages of CWCA, CWFA and EAFS have been measured and compared.

Using CWFA at a low dosage and CWCA at a high dosage improved flow-ability and reduced the probability of segregation in the SCC. While the introduction of CWCA and CWFA improved the rate of strength gain in the SCC, their introduction had no significant impact on the overall compressive strength of the SCC.

Additionally, the introduction of EAFS reduces the probability of segregation in the SCC and its introduction at any dosage at or below $15 \%$ increases the compressive strength of the SCC, if only marginally.

It would be worth exploring how the compressive strength of the SCC would change if samples were tested at 56 days of age. Furthermore, the results of this study could be expanded in the future to include possible hybrid mixes, containing optimum dosages of CWCA, CWFA and EAFS that can improve both fresh and hardened properties.

\section{Acknowledgement}

The authors would like to acknowledge Mr. Tahir Afrasiab, Mr. Adel Jumaah, Mr. Abdulaziz Majeed and Ms. Sarah Al-Muhanna for their contributions and hard work in completing this study. Additionally, the authors would like to thank United Steel Industrial Company and Gulf Shores Company for Sanitary Wares and Construction Building Materials for generously providing their waste materials for their use in this study. Last but not least, the authors would like to thank Combined Group Contracting Co. and Sika for providing the required concrete raw materials and superplasticizer, respectively.

\section{Funding Information}

This project was funded "partially" by the Kuwait Foundation for the Advancement of Science under project code: PN18-15EV-01.

\section{Author's Contributions}

Ali Behbehani, Mhd Hazem Al-Swwaf and Najem Al-Matroud: Prepared, batched, mixed, cured and tested the concrete used in this study.

Sayed Mohamad Soleimani: Supervised the work carried out, collected, analyzed the results and reviewed the manuscript.

Abdel Rahman Alaqqad: Compiled the results and wrote the manuscript.

\section{Ethics}

This article is original and contains unpublished material. The corresponding author confirms that all of the other authors have read and approved the manuscript and no ethical issues involved.

\section{References}

Anderson, D.J., S.T. Smith and F.T.K. Au, 2016. Mechanical properties of concrete utilizing waste ceramic as coarse aggregate. Constr. Build. Mater., 117: 20-28.

DOI: $10.1016 /$ j.conbuildmat.2016.04.153

Arulsivanantham, P. and R. Gokulan, 2017. A review on self compacting concrete. Int. J. ChemTech Res., 10: 62-68.

ASTM International, 2017. ASTM C1621/C1621M-17 standard test method for passing ability of selfconsolidating concrete by J-Ring.

Australasian (Iron and Steel) Slag Association, 2019. Electric arc furnace slag.

Awoyera, P.O., J.M. Ndambuki, J.O. Akinmusuru and D.O. Omole, 2016. Characterization of ceramic waste aggregate concrete. HBRC J., 14: 282-287. DOI: $10.1016 /$ j.hbrcj.2016.11.003

British Standards Institution, 1998. BS EN 1235010:2010: Testing fresh concrete. Self-compacting concrete. L Box Test. 
British Standards Institution, 1998. BS EN 123509:2010: Testing fresh concrete. Self-compacting concrete. V Funnel Test.

Gomes, M. and J. de Brito, 1999. Structural concrete with incorporation of coarse recycled concrete and ceramic aggregates: Durability performance. Mater. Struct., 42: 663-675.

DOI: $10.1617 / \mathrm{s} 11527-008-9411-9$

Halicka, A., P. Ogrodnik and B. Zegardlo, 2013. Using ceramic sanitary ware waste as concrete aggregate. Constr. Build. Mater., 48: 295-305. DOI: 10.1016/j.conbuildmat.2013.06.063

Juan, A., C. Medina, M.I. Guerra, B. Llamas and J.M. Morán et al., 2010. Re-use of construction and demolition residues and industrial wastes for the elaboration or recycled eco-efficient concretes. Span J. Agric. Res., 8: 25-34.

DOI: $10.5424 /$ sjar/2010081-1140
Khayat, K.H., 1999. Workability, testing and performance of self consolidating concrete. ACI Mater. J., 96: 346-354. DOI: 10.14359/632

Medina, C., M. Sánchez de Rojas and M. Frías, 2012. Reuse of sanitary ceramic wastes as coarse aggregate in eco-efficient concretes. Cement Concrete Comp., 34: 48-54.

DOI: 10.1016/j.cemconcomp.2011.08.015

Senthamarai, R.M. and P.D. Manoharan, 2005. Concrete with ceramic waste aggregate. Cement Concrete Comp., 27: 910-913.

DOI: 10.1016/j.cemconcomp.2005.04.003 